\title{
Move over Darwin
}

\section{A look at the co-discoverer of natural selection. Neo-Wallaceism anyone?}

\section{In Darwin's Shadow: The Life and Science of Alfred Russel Wallace by Michael Shermer Oxford University Press: 2002. 368 pp.

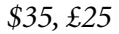 \\ James Mallet}

"In the beautiful forms of crystallization on his window [the scientist] recognizes the action of laws which may also have a part in the production of the similar forms of plants and many of the lower animal types. Thus the simplest facts of everyday life have for him an inner meaning, and he sees that they depend on the same general laws that are at work in the grandest phenomena of nature." Barely out of his teens in 1843, Alfred Russel Wallace here displayed a deep appreciation of the materialism and parsimony that led to his major discovery: natural selection. Fifteen years later, Wallace's letter to Charles Darwin from the Indonesian island of Ternate prompted a revolution in biology. After years of dithering and procrastination instead of publishing his theory of natural selection, Darwin found that Wallace had independently hit upon the same idea.

How could Wallace, the co-discoverer of the supreme materialistic theory of evolution, then be seduced by spiritualism, oppose vaccination, and argue that "an Overruling

Intelligence has watched over" human evolution and natural selection? Darwin was appalled: "You write like a metamorphosed (in retrograde direction) naturalist. And you, the author of the best paper that ever appeared in the Anthropological Review! Eheu! Eheu! Eheu! - Your miserable friend, C. Darwin." Wallace's paradoxical beliefs form the major subtext of this new biography. Michael Shermer, the editor of Skeptic magazine, clearly relishes the challenge of explaining Wallace's pseudoscience.

Wallace wrote that he "pondered much on the incomprehensible subjects of space, eternity, life and death. I think I have fairly heard and fairly weighed the evidence on both sides, and I remain an utter disbeliever." Religion, at least in 1861, could not explain Wallace's abandonment of the materialism he had announced 18 years earlier, and he never became conventionally religious.

Shermer follows earlier Wallace commentators, Charles H. Smith and the late Stephen Jay Gould, and interprets Wallace as a "hyper-selectionist". The capacities for art, music and philosophy are present even in "savage races", where they are not useful or beneficial, according to Wallace; therefore, they could not be explained by natural selection. Because these abilities resulted ultimately in the flowering of human culture,

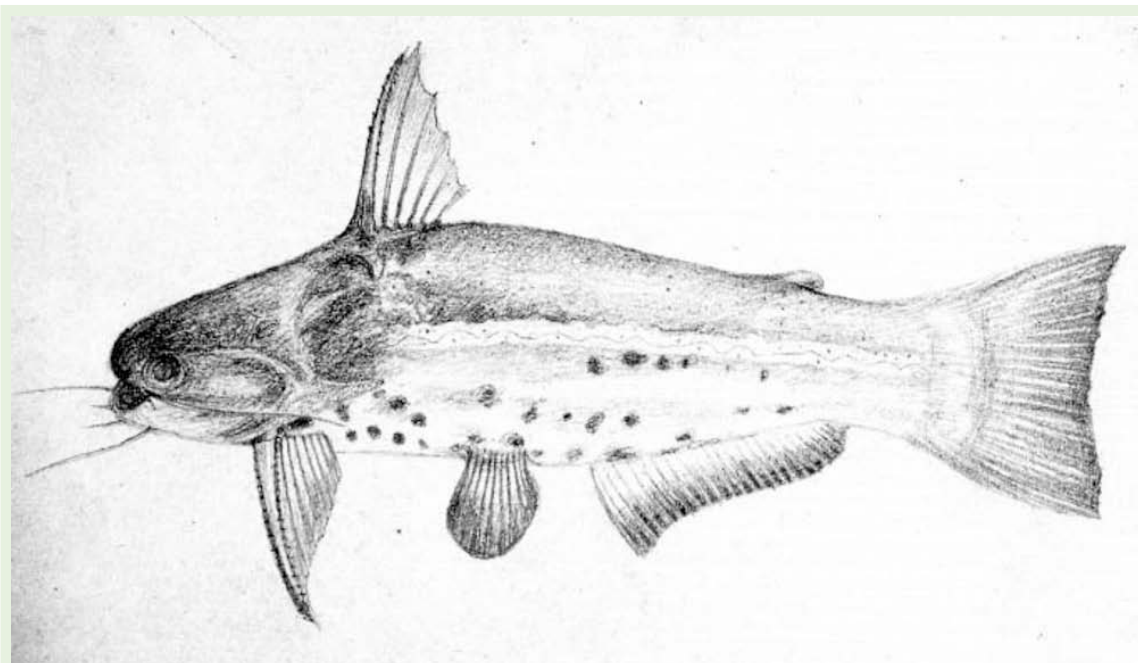

\section{Survival of the fishes}

Alfred Russel Wallace's first large expedition to South America nearly ended in disaster. After four years collecting specimens up the Rio Negro and Rio Uaupés, Wallace was returning home when the ship he was travelling on caught fire. He escaped with only a tin box containing a few personal belongings and a collection of drawings of fishes and palms - the rest of his extensive collection was lost forever. Now Mônica de Toledo-Piza Ragazzo has organized the first publication of this collection of drawings, one of which is reproduced here, in Fishes of the Rio Negro: Alfred Russel Wallace (University of São Paulo, 120 Brazilian reals, US $\$ 50$ ).

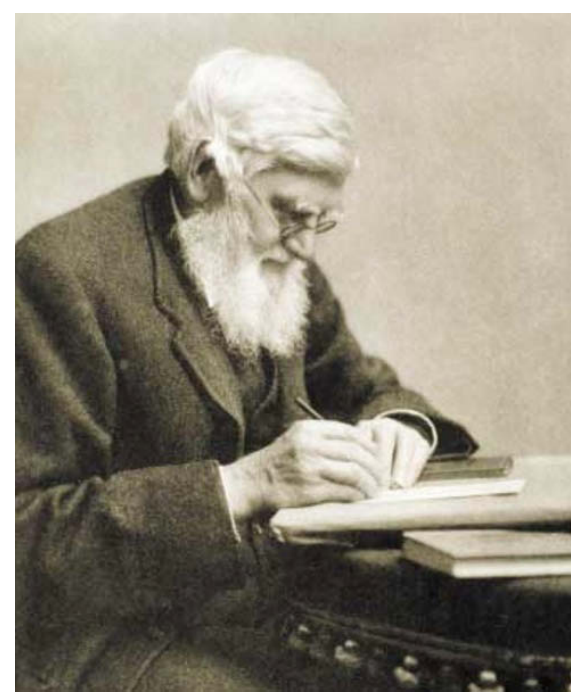

Change of heart: Alfred Russel Wallace abandoned natural selection for spiritualism.

Wallace felt that some sort of benevolent law, in addition to natural selection, must be directing human evolution. It was his strong belief in natural selection that made it supposedly logical that he should reject the principle for human origins. Also consistent was Wallace's membership of the antivaccination movement (vaccination would be necessary only if humans were not already optimal) and his support for human improvement by socialism and spiritualism.

The idea of Wallace as a hyper-selectionist is now decades old, dating from Gould's charming 1980 essay in Natural History. The obvious, almost forgotten but plausible alternative is that Wallace, like most of us, was simply inconsistent. His intellectual courage failed him, and he edged away from the yawning abyss into which the logic of materialism and natural selection led. He became a kind of theist, arguing that "intelligent beings, acting through natural and universal laws" directed human evolution for our benefit.

In contrast, dogged exploration of the limits of natural selection led Darwin to explain such oddities as rudimentary organs and the apparently non-adaptive and flamboyant colours of male animals. Today, Darwin's viewpoints on these topics are completely vindicated: for example, the idea that peacock tails evolved by female choice is strongly supported by experiment. After the 1860s, Wallace could never stomach such a quirky kind of evolution, and argued strongly against it. But Darwin wasn't always right: he erroneously accepted the inheritance of acquired characters (lamarckism) in evolution, whereas Wallace rejected it. The problem here was the data. Wallace's zeal for natural selection 
probably explained his aversion to lamarckism, despite the evidence, which apparently supported it; Darwin believed the faulty data.

Shermer covers all the other aspects of Wallace that one wishes and expects. A good sceptic, Shermer carefully debunks conspiracy theories found in other biographies, such as that Darwin and his friends unfairly took the credit for natural selection from Wallace. Shermer uses new manuscript information to show that such a plot is highly unlikely, and that Wallace strongly approved of the "gentlemanly arrangement" to co-publish with Darwin in 1858 as soon as he heard of it. Indeed, Shermer makes it clear that the young Wallace's reputation and career benefited greatly from the joint publication of natural selection in the Proceedings of the Linnean Society.

Shermer is weaker on the background, particularly on species and the history of evolutionary ideas. Much of it seems derivative of Ernst Mayr's Growth of Biological Thought (Harvard University Press, 1982). Shermer unquestioningly accepts Frank Sulloway's statistical analyses, putatively showing that "later-borns" such as Wallace are more radical scientists than first-borns. This seems oddly uncritical for the editor of Skeptic, and it is easy to think of exceptions.

Shermer's description of Wallace's life is excellent, and the bibliography of his publications and manuscript sources is the most complete to date. Shermer befriended the Wallace heirs and accessed their archive to gain new insights into their ancestor (this collection has since been acquired by the Natural History Museum in London). The book is full of interesting anecdotes, for instance that Wallace made a bet with a flat-Earther, John Hampden, and won $\mathfrak{E} 500$ by means of a clever experiment on the Old Bedford Canal. Sadly, Wallace had to spend more than that on lawyers to recover the money from his opponent, who was clearly not a good loser.

Biographers and historians like to find a new angle on their subject, a selling point for their work that lasts until the next treatment comes along to disprove it. But wishful thinking has led to a lot of nonsense being published about Wallace, and about his supposed conflict with Darwin in particular. When it comes to Wallace's travels, discoveries, public life and beliefs, truth is at least as strange as fiction, and it is a relief that Shermer entertains the reader by getting the facts of Wallace's life right. Let's hope that most of the contrarian ideas that can be twisted out of Wallace's life have already been aired. But as the spate of interest in the history of evolution continues, more new Wallace biographies are on the horizon. I wonder what the next angle will be? James Mallet is in the Department of Biology, University College London, Wolfson House, 4 Stephenson Way, London NW1 2HE, UK.

\section{Mapping biodiversity}

World Atlas of Biodiversity: Earth's Living Resources in the 21st Century

by Brian Groombridge \& Martin D. Jenkins University of California Press: 2002. 340 pp. $\$ 54.95, \mathfrak{E 3 7 . 9 5}$

\section{Kevin J. Gaston}

The sheer pervasiveness of human activities is hard to envisage. Conventional maps of the distribution of the present 6 billion or so humans illustrate the peaks and lows of those presently residing on the major landmasses. But they fail to capture the large numbers of people who may pass through areas that hold no or rather small resident populations, the many thousands of individuals who at any given time are dispersed across or under the oceans (in ships or oilrigs, for example) or in the atmosphere (in aircraft), or the handful that are out in space. Track all of these activities over even a moderate period and much of the Earth would have been criss-crossed innumerable times.

Humans are the most widely distributed 'terrestrial' vertebrate, vastly more abundant than other species of such body size. We operate an enterprise of bewildering magnitude and complexity to sustain these individuals and the societies to which they belong. It is hardly surprising that in the face of these pressures, much of the variety of life on this planet, be it species, populations or genes, is being steadily expunged. What is more baffling is that apparently so few people have grasped the magnitude of the problem and the breadth of its implications. On closer reflection, the media attention that is paid to these issues, and the general availability of appropriate resources (articles, books and television programmes, for instance), is considerably less than for many other fields of significant human concern. Those of us attempting to maintain biodiversity should not be beguiled into generalizing from the state of our own awareness, nor into overestimating media coverage just because we pay attention to it when it does occur.

This book by Brian Groombridge and Martin Jenkins of the United Nations Environment Programme's World Conservation Monitoring Centre sets out to provide an overview of the current state of global biodiversity. The authors try to step into the breach and make the facts more accessible to a wider readership beyond the community of professional biologists. The book is effectively a second edition of a volume published two years ago, but it has been much extended and updated, with a hopeful eye to renewed interest in the area being spurred by the recent Johannesburg World Summit on Sustainable Development.

The volume is well written, and there is little with which to disagree. The coverage is reasonably comprehensive and remarkably up to date, with many of the sources cited having been published in the past 18 months. The first two-thirds of this book comprises chapters addressing, in some detail, the nature and origins of biodiversity, its dynamics and distribution, and its relationship to humans both now and in the future. These pages are stuffed full of striking photographs, tables, graphs and maps. The value of some of these is perhaps a little

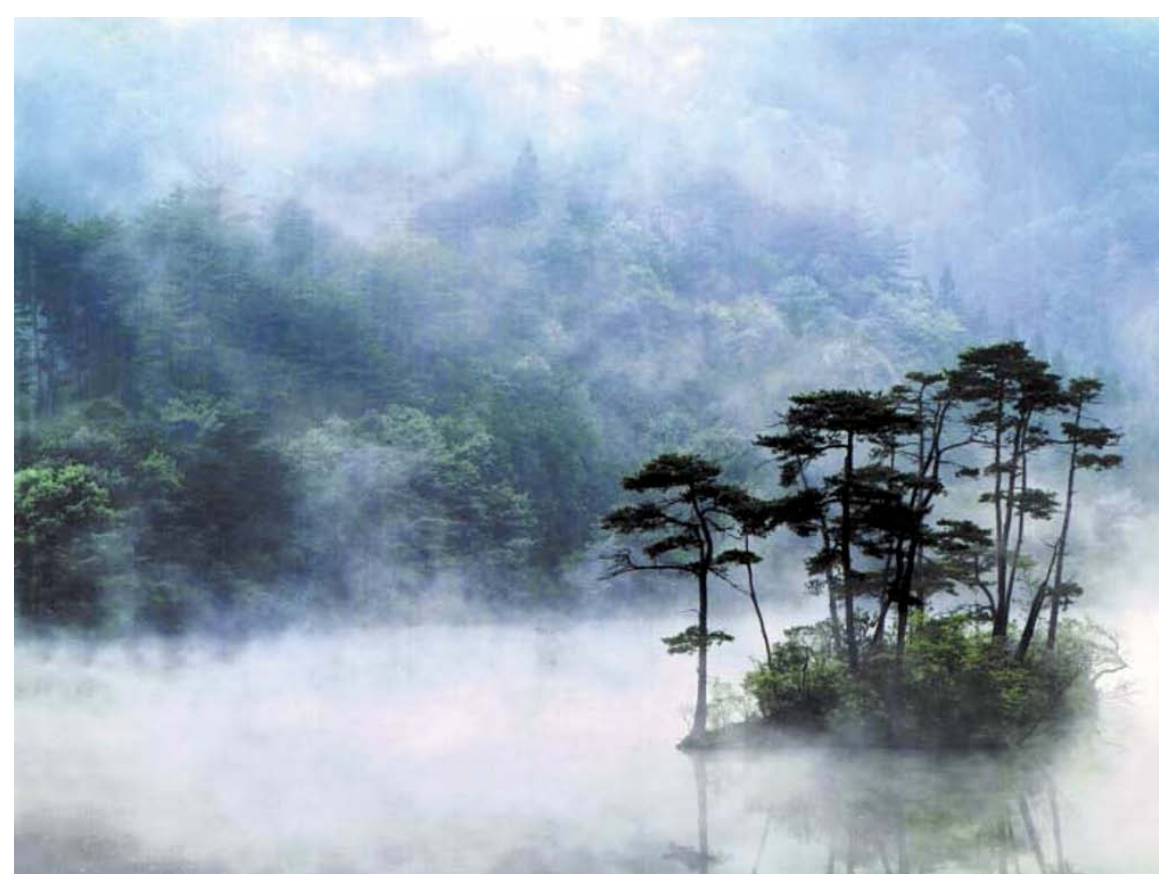

The mist rises: protecting biodiversity means raising awareness about the issue among policy-makers. 